\title{
UNIVERSIDADE NO BRASIL: COLONIALISMO, COLONIALIDADE E DESCOLONIZAÇÃO NUMA PERSPECTIVA NEGRA
}

Nádia Maria Cardoso da Silva ${ }^{\mathrm{i}}$

\begin{abstract}
Resumo: Apresentamos o ensino superior brasileiro como criação que fortalece o colonialismo português no Brasil e a universidade brasileira, surgida na década de 1920, como lugar de produção de conhecimento a partir da colonialidade de poder/saber sobre negros, negras e indígenas, sustentando o eurocentrismo e consolidando o racismo/sexismo epistêmico. No século XXI, os Movimentos Negros desafiam a universidade brasileira a enfrentar tais desafios através da descolonização do conhecimento acadêmico, pois, ainda que estejam adotando políticas de ampliação do acesso dos negros e negras, encaram dificuldades para operar mudanças epistemológicas que enfrentem o silenciamento epistêmico de intelectuais negros e negras. A partir da perspectiva decolonial latino-americana, visibilizamos a experiência de alguns intelectuais negros e negras como estratégia de combate ao racismo/sexismo epistêmico no Brasil.
\end{abstract}

Palavras-chave: Universidade; Racismo/sexismo epistêmico; Colonialidade; Descolonização; Movimentos negros.

\section{UNIVERSITY IN BRAZIL: COLONIALISM, COLONIALITY AND DECOLONIZATION IN A BLACK PERSPECTIVE}

\begin{abstract}
We present how Brazilian's college education as a creation to strenghten portuguese colonialism in Brazil and how the Brazilian university, emerged in the 1920's, as a place of production of knowledge based on the coloniality of power/knowledge over blacks and indigenous people, sustaining the eurocentrism and consolidating epistemic racism and sexism. In the 21st century, the Black Movements defy the brazilian university to face such challenges through the decolonization of academic knowledge, because, even though brazilian universities are adopting policies to increase access of black people, they find difficulties to undergo epistemological changes that face the epistemic silencing of the black intellectuals. From the Latin American decolonial perspective, we make visible the experience of some black intellectuals as a strategy to combat racism/epistemic sexism in Brazil.
\end{abstract}

Keywords: University; Racism/epistemic sexism; Coloniality; Decolonization; Black movements.

\section{Universidade no Brasil: lugar de conhecimento colonizado}

Partimos da constatação do quanto o conhecimento acadêmico no Brasil é um forte traço da permanência da colonialidade de poderes na sociedade pós-colonial brasileira, entendida, de 
acordo com o peruano Anibal Quijano (2005), como um contexto de pós-independência, no qual as elites branco-mestiças mantêm intactas as hierarquias raciais sobre negros e indígenas, ou seja, um cenário de independência sem descolonização. Isso parece sugerir que para o Brasil passar da fase da pós-independência para a "descolonização", é estratégico a "descolonização" da universidade, criada nesse contexto.

A criação do o ensino superior brasileiro por D. João VI, com a vinda da Coroa Portuguesa para o Brasil, em 1808, tinha a firme intenção de estabelecer no país instituições centralizadoras que reproduzissem de forma perfeita o antigo domínio colonial (SCHWARCZ, 1993, p. 23). Esse foi o momento de transferência da Corte e do domínio metropolitano para o Brasil que, através da criação de diversas instituições, transformava a colônia na sede provisória da monarquia portuguesa e em um centro produtor e reprodutor de sua cultura e memória, com o fim de garantir o melhor controle colonial: Profundamente vinculados aos modelos metropolitanos, os primeiros centros de saber enxergavam o Brasil ora como um espelho, ora como extensão dependente da corte portuguesa e a ela subserviente (SCHWARCZ, 1993, p. 24). Cursos superiores de Medicina, Direito, Engenharia e de Academias Militares são instalados no Brasil com a vinda da Coroa Portuguesa e a elevação da colônia à condição de Reino Unido junto a Portugal, para atender às elites coloniais brancas escravocratas. Esse é o contexto brasileiro de colonização com escravidão racial, cuja estratégia de aniquilamento do negro enquanto sujeito de direitos contou com a desconstrução semiótica do seu corpo, apoiada na categoria semântica humano vs. não-humanos, para se outorgar um poder-fazer de transformar o outro - o escravizado - em sua posse, numa total demonstração da morte semiótica do sujeito (CASTRO, 2007).

Com a volta de D. João VI para Portugal, seu filho, D. Pedro, apoia a fundação de novas instituições de saber, como as escolas de Direito que tinham como meta a elaboração de um código único e desvinculado da tutela colonial, bem como a formação de uma elite intelectual nacional mais autônoma (SCHWARCZ, 1993, p. 24). O problema é que a autonomia da intelectualidade brasileira foi limitada pela consolidação de um pensamento social brasileiro que permaneceu colonizado, importando teorias europeias para interpretação negativa da diferença étnico-racial da sociedade brasileira. Moura (1988) fala de um pensamento social subordinado que ao produzir estudos acadêmicos invocando uma imparcialidade científica inexistente nas ciências sociais, assessoram a formação do imaginário social racista dos 
brasileiros. Para entender esse processo, temos que revisitar o caso de "descolonização" do Brasil.

É nesse contexto descrito acima que devemos entender os anos 70 do século XIX, que, para Schwarcz (1993), constituem um marco da tentativa de esboçar uma nova nação liberta das amarras do Império, embora sem um novo projeto político definido. Schwarcz (1993) registra a atuação destacada dos institutos históricos nos anos 70 do século XIX, que, ao congregarem uma elite intelectual e econômica de diferentes províncias vinculados ao monarca D. Pedro II, começavam a escrever a história oficial do país, formando o primeiro grupo de intelectuais brasileiros. Para compor esse cenário intelectual, Schwarcz (1993) registra ainda que, apesar das Faculdades de Direito de São Paulo e de Recife estarem preocupadas em elaborar um código nacional, São Paulo adotava modelos liberais de análise, enquanto no Recife predominava o social-darwinismo de Haechel e Spencer. Schwarcz (1993, p. 28) denomina esse momento como de

uma espécie de imperialismo interno, [...] [no qual o Brasil passava] de objeto a sujeito das explicações, ao mesmo tempo que se faziam das diferenças sociais variações raciais, [pois] os mesmos modelos que explicavam o atraso brasileiro em relação ao mundo ocidental passavam a justificar novas formas de inferioridade, [já que] negros, africanos trabalhadores, escravos e exescravos - 'classes perigosas' a partir de então, nas palavras de Sílvio Romero - transformavam-se em 'objetos de sciência'. [...] Era a partir da ciência que se reconheciam diferenças e se determinavam inferioridades (SCHWARCZ, 1993, p. 28).

A autora conclui que a "sciência" que chega ao Brasil em finais do século XIX, não é tanto uma ciência de tipo experimental, ou a sociologia de Durkheim ou de Weber pois o que aqui se consome são modelos evolucionistas e social-darwinistas originalmente popularizados enquanto justificativas teóricas de práticas imperialistas de dominação (SCHWARCZ, 1993, p. 30).

Schwarcz (1993) ainda nos chama a atenção para o fato de que as elites brancas da monarquia imperial brasileira da década de 70 do século XIX eram grandes leitoras da literatura produzida na Europa e nos Estados Unidos, pois tinham como objetivo diferenciar-se das demais repúblicas latino-americanas e aproximando-se dos modelos europeus de conhecimento e civilidade, já que era como sociedade científica e moderna que o Brasil de finais do século pretendia se auto-representar (SCHWARCZ, 1993, p. 30-31) nos institutos, nos jornais e nos romances, sob o domínio do Imperador D. Pedro II, o qual costumava dizer 
que a "sciência sou eu". Schwarcz (1993) registra esse objetivo da intelectualidade brasileira através do jornal Provincia de São Paulo - criado em 1875, futuro O Estado de São Paulo - o qual publiciza em suas páginas todo um ideário evolutivo-positivista, divulgando cotidianamente mestres europeus, dentre eles Darwin, Spencer e Comte, como se livremente se associassem conceitos como ciência e modernidade (p. 32).

Nesse ensino superior, por sua vez, vai se consolidando o racismo científico brasileiro, ou seja, práticas acadêmicas e intelectuais, a partir da reelaboração das teorias raciais europeias, que consolidam narrativas que fundamentam políticas de valorização do branqueamento do país, fundamentado pelas "convicções" científicas de inferioridade negra e indígena e de superioridade branco-europeia. Vinculados a essas instituições científicas, Schwarcz (1993, p. 37) ressalta que os intelectuais brasileiros estavam convictos de que passavam a falar de um lugar reconhecido socialmente, que lhes davam legitimidade para discutir e apontar os impasses e perspectivas que se apresentavam para o país. Escolhem falar e analisar o Brasil a partir das teorias raciais, importadas, mas não mais valorizados na Europa, em detrimentos a outros modelos de sucesso na época, pois esses modelos evolucionistas e darwinistas sociais traziam a sensação de proximidade com o mundo europeu e de confiança na inevitabilidade do progresso e da civilização (SCHWARCZ, 1993, p. 34).

Entender esse processo de criação e difusão mundial do racismo científico, da ideologia da superioridade racial europeia e sua reprodução pelos intelectuais e acadêmicos brasileiros do século XIX é fundamental para entendermos a colonialidade intelectual que ainda vivemos no Brasil e que fundamenta a difusão contemporânea de um conhecimento colonizado, de base eurocêntrica, dificultando a vivência de uma diversidade epistêmica na universidade brasileira. Ao importar tais teorias raciais, os intelectuais brasileiros estavam importando, para o país, a hegemonia europeia-ocidental e, consequentemente, o lugar da Europa como Eu superior e, especialmente, a sua dominação epistemológica (RAMOS, 1995). Assim, apesar da independência administrativa da colonização portuguesa, importávamos outras colonizações, formando o nosso contexto de colonialidades, especialmente epistemológicas, nos produzindo como sombra da Europa e nos afirmando como seu outro, ainda que a intenção fosse nos encobrir como outro e nos constituir como si do mesmo europeu. Para Silveira (1999), o racismo científico que surge na Europa, no século XIX, foi uma parte importantíssima da estruturação de uma hegemonia abrangendo todo o globo terrestre, ocorrida pela primeira vez na história da humanidade: 
A Europa, em seu processo de afirmação, definia-se como superior em contraposição a todo o resto do mundo conhecido e a ciência em ascensão tornava-se um território privilegiado para a legitimação desta reivindicação. A História natural passou então a traçar um quadro bastante vasto das populações de toda a Terra, assumindo a raça como critério válido de classificação e influência determinante em todas as realizações humanas, sociais, políticas e culturais. Abria-se assim todo um imenso território para a colonização intelectual, com a consequente criação de numerosas disciplinas científicas que passariam a esquadrinhar o globo, à procura de novas e palpitantes explicações raciais hierarquizantes (SILVEIRA, 1999, p. 100).

Essas teorias raciais europeias é que são copiadas ou importadas pela esfera acadêmica e intelectual brasileira para pensar o Brasil e acolhidas pela esfera política, em finais do século XIX. A sua reelaboração tinha como alvo principal os ex-escravizados, já que, num cenário de fim da escravidão racial no Brasil, a grande questão posta nesse momento era como o Brasil enquanto nação poderia alcançar o progresso e a civilização, cujo modelo era a Europa, com uma imensa população majoritariamente negra e indígena? Apesar de concordarem que o Brasil era uma nação inviável se não resolvesse o problema da diversidade étnico-racial de sua população, em resposta a essa questão, havia, por um lado, os intelectuais que eram contra a miscigenação já que a entendiam como geradora de uma degeneração racial, pois acreditavam que na mistura racial predominava as características inferiores dos grupos não brancos. E, por outro lado, havia os intelectuais brasileiros que eram a favor da miscigenação, pois acreditavam que na mistura predominava as características superiores dos brancos. Ambos os grupos estavam convictos da superioridade branca e da inferioridade negra e indígena, pois essa era a episteme dominante no Brasil, baseado na escolha dos intelectuais brasileiros de operar segundo a lógica da, utilizando expressão de Guerreiro Ramos (2005), transplantação da epistemologia europeia para os nossos trópicos. De 1850 até a primeira metade do século 20, a miscigenação foi apresentada tanto como solução quanto problema para o Brasil (SEYFERT, 2002; SILVA, 1989; SCHWARCZ, 1996).

O discurso acadêmico do maranhense, mas quase baiano, Nina Rodrigues (1982) morador da cidade do Salvador, fundador da Faculdade Baiana de Medicina e um dos mais importantes intelectuais do racismo científico no Brasil - é o mais forte na afirmação da miscigenação como problema. As práticas discursivas de Nina Rodrigues interpretam a miscigenação como "degeneração", já que faz prevalecer as características negativas dos negros 
e indígenas. Em sua obra, Os Africanos no Brasil, afirma o caráter "científico" da inferioridade racial do negro:

O critério científico da inferioridade da Raça Negra nada tem de comum com a revoltante exploração que dele fizeram os interesses escravistas dos norteamericanos. Para a ciência não é esta inferioridade mais do que um fenômeno de ordem perfeitamente natural, produto da marcha desigual do desenvolvimento filogenético da humanidade nas suas diversas divisões ou secções. [...] A Raça Negra no Brasil, por maiores que tenham sido os seus incontestáveis serviços à nossa civilização, por mais justificadas que sejam as simpatias de que a cercou o revoltante abuso da escravidão, por maiores que se revelem os generosos exageros dos seus turiferários, há de constituir sempre um dos fatores de nossa inferioridade como povo [...]. (RODRIGUES, 1982, p. 5).

Essa posição de Rodrigues parece ser uma cópia dos princípios do racismo científico europeu, pois, de acordo com Silveira (1999), os cientistas do século XIX na Europa, mesmo quando eventualissimamente discordaram da agressão colonial ou da escravização dos africanos, deixaram fora de discussão a superioridade do europeu (SILVEIRA, 1999, p. 90), já que o racismo científico surge como sustentação desse axioma, ocasionando mudanças nos modos de legitimação do poder e reestruturando o imaginário coletivo, a educação pública, os padrões da credibilidade e os mecanismos de formação da opinião mundialmente. Agassiz e Gobineau são dois autores que fundamentam Nina em Os Africanos no Brasil. Assim, ainda em maio de 1988, mês e ano da abolição da escravidão, vários jornais brasileiros publicavam o artigo de Nina Rodrigues onde defendia a ideia de que os homens não nascem iguais. Mais tarde, publica o livro As raças humanas e a responsabilidade penal no Brasil (1894) defendendo a necessidade da existência de dois códigos penais no país - um para negros, outro para brancos - já que esses dois grupos apresentavam entre si diferentes graus de evolução humana (SCHWARCZ, 1996).

Assim, apesar da etnografia de Nina Rodrigues sobre as culturas africanas e negrobrasileiras do século XIX ter o mérito da qualidade e quantidade de informações que traz sobre elas, sua análise dessa etnografia é exemplar da aplicação sobre a Bahia e suas populações africanas e negras da ciência racista e eurocêntrica produzidas na Europa no século XVIII. As informações são lidas sempre a partir do racismo científico europeu predominante lá no século anterior: inferioridade intelectual, social e religiosa dos negros bantu em relação aos sudaneses; evolucionismo aplicado às religiões no Brasil onde o catolicismo aparece no topo e as religiões bantu e indígena na base da sua hierarquia religiosa; os movimentos rebeldes dos escravizados 
na primeira metade do século XIX, principalmente dos negros malês, explicada pela fanatismo islâmico, etc. Apesar de reconhecer o Quilombo de Palmares como um Estado Negro, defende que devemos respeito às armas portuguesas e coloniais por ter destruído de uma vez por todas esse quilombo - "uma ameaça à civilização do futuro povo brasileiro", pois "refratário ao progresso inacessível à civilização que Palmares vitorioso teria plantado no coração do Brasil”, considerando-o um "novo Haiti".

Mas o projeto político de miscigenação entre brancos e não brancos foi hegemônico como solução para a questão de como o Brasil poderia alcançar o progresso e a civilização europeia. $\mathrm{O}$ que predominou político-academicamente foi a defesa da miscigenação motivada pela convicção de que quando nos misturamos, predominavam as características superiores dos brancos europeus. Representativo dessa ideia era Oliveira Viana, vinculado ao Instituto Histórico e Geográfico do Brasil, segundo o qual o branqueamento da população brasileira era a única saída para o "progresso" do país, valorizando as características dos povos arianos que, segundo Viana, dirigiram o processo de colonização e formação da sociedade brasileira.

Freyre, por sua vez, um dos mais populares defensores da miscigenação, produz CasaGrande e Senzala dividido entre duas epistemes - as teorias raciais, que dominava o debate acadêmico brasileiro, e a antropologia cultural de Boas que naquele momento dava novos rumos aos estudos antropológicos na academia norte-americana. É significativo o fato de que essa sua obra se origina de sua tese de doutorado. Mas, por que, apesar de tais teorias não serem mais consideradas como verdade científica nem na Europa - em processo de desenvolvimento capitalista industrial - nem nos EUA, era a episteme dominante no Brasil? Schwarcz (1993) nos alerta que esses intelectuais brasileiros

[...] tenderam a adotar os modelos evolucionistas, em especial socialdarwinistas, já bastante desacreditados no contexto europeu, que tinham como objeto central o estudo das raças, [...] [pois o que interessava era] adaptar o que 'combinava' - da justificação de uma espécie de uma hierarquia natural à comprovação da inferioridade de largos setores da população. (p. 41)

Nos termos dos estudos descoloniais latino-americanos, esses intelectuais estavam à serviço das elites branco-mestiças, a qual Freyre pertencia, para consolidação da colonialidade dos poderes no Brasil pós-independência e pós-abolição, portanto, para manter a dominação colonial branca sobre negros e indígenas. 
A produção intelectual de Freyre respondia perfeitamente a tais interesses - de forjar uma identidade nacional distanciada dos grupos que significavam, para essas elites, o atraso do Brasil: negros e indígenas. Para tanto, a celebração do mestiço apaga a etnia/cor da população brasileira. Sua tese principal de que a miscigenação democratizou racialmente o Brasil - ainda que rompa com as tendências intelectuais às quais Nina Rodrigues se filia, de que a miscigenação levaria à degeneração racial no Brasil, colaborou em grande medida para a manutenção da dominação racial na sociedade brasileira. E não podemos esquecer de que o que Freyre faz é radicalizar a tese de Oliveira Viana baseada na ideia de que a miscigenação embranqueceria o país - pois prevalecia as características superiores dos brancos. Suas ideias influenciam enormemente o ambiente acadêmico brasileiro. Em 1935, Freyre funda o curso de sociologia na Faculdade de Direito de Recife, à qual Silvio Romero já era vinculado, e na Universidade do Distrito Federal, onde também ensinou antropologia social e cultural. Portanto, participa como catedrático das primeiras universidades do país, influenciando o pensamento social brasileiro tanto acadêmico quanto popular.

Criada no século XX, a universidade brasileira, enquanto signo de prestígio e de poder, passa a ser disputada entre elites e classes médias brancas no Brasil. É em 1920 que é criada a primeira universidade brasileira - a Universidade do Brasil - cuja perspectiva era apenas reunir formalmente as escolas superiores já existentes. A partir daí, durante todo o século XX, a universidade brasileira se constituiu num projeto de interesses das elites e camadas médias brancas brasileiras, muitas vezes fundamentado por uma lógica de desenvolvimento centrado nos seus interesses econômicos de raça/classe (DURHAN, 1996).

A universidade no Brasil que surge na década de 20, além de herdar essa tradição de conhecimento acadêmico, é instituída sob uma relação de escrita/conhecimento europeu e silêncio negro/indígena, como dizia Said (1990), como vontade de poder de branco-mestiços sobre não-brancos brasileiros. Um exemplo disso diz respeito ao campo dos estudos das "relações raciais" na antropologia e sociologia brasileira, que se constituíram como objeto de conhecimento historicamente produzido por acadêmicos brancos cuja epistemologia baseia-se no estudo sobre negros, por isso mesmo, a noção de estudos sobre as 'relações raciais'mantém o mito de uma horizontalidade entre os grupos racialmente diferenciados (FIGUEIREDO; GROSFOGUEL, 1997, p. 36). Essa tradição acadêmica brasileira, na qual os sujeitos do conhecimento são os grupos brancos e os objetos de conhecimento são os negros e indígenas, se manteve, especialmente no que diz respeito ao lugar dos negros e negras, nas 3 fases desses 
estudos das "relações raciais" no campo da sócio-antropologia no Brasil, apontados por Figueiredo e Grosfoguel (2007).

O primeiro momento diz respeito aos intelectuais do século XIX que aplicaram, sobre negros e indígenas, a epistemologia branco-europeia, lá já fora de moda, mas que tinha fundamentado cientificamente o seu projeto de conquista e colonização do mundo desde o século XVI. Figueiredo e Grosfoguel (2007, p. 36) dizem sobre esse momento:

A primeira geração estava preocupada com o futuro da nação brasileira, condenada pelos efeitos "maléficos" da mistura de raças. Nesse período, os estudos vislumbravam uma única saída: o clareamento, ou embranquecimento, da população brasileira a partir da mistura das raças em gerações consecutivas, ou seja, havia uma crença de que mestiçagens sucessivas levariam, inevitavelmente, ao desaparecimento da população negra.

O segundo momento diz respeito à interpretação do Brasil a partir de Freyre, afirmando a miscigenação como identidade nacional que produziu uma sociedade harmônica nas suas relações raciais e democrática no Brasil: o culturalismo de Freyre acabou por consolidar a crença na democracia racial brasileira, paradigma interpretativo vigente pelo menos até o final dos anos 1980 (FIGUEIREDO; GROSFOGUEL, 2007, p. 36). O terceiro momento é caracterizado pela institucionalização da sociologia e, consequentemente, pela adoção de técnicas de pesquisa e reflexões teóricas mais rigorosas (Idem), momento no qual Donald Pierson, da Escola de Chicago, que influenciará bastante a sociologia brasileira, e a antropóloga estadunidense Ruth Landes passam a estudar os negros e a cultura negra na Bahia, e a Unesco encomenda diversas pesquisas no Brasil a pesquisadores brancos brasileiros sobre nossas harmoniosas “relações raciais". Para Grosfoguel e Figueiredo (2007), a configuração do campo dos estudos das relações raciais no Brasil evidencia a existência de um campo institucionalizado e hegemonizado por perspectivas e epistemologias euro-brasileiras (p. 37).

A ciência que se forja nessa universidade do século XX no Brasil não é mais a ciência do racismo científico, mas mantém o modo dominante do conhecimento ocidental - o eurocentrismo. Said (1990), que compreende o eurocentrismo como um estilo ocidental de dominação, na qual a cultura europeia, através da colonização e imperialismo, administrou e produziu outros como sistema de verdade - sociológica, antropológica, histórica, política, biológica, etc., afirma que todo o conhecimento produzido pelo europeu sobre o outro, seja antropológico, sociológico, histórico, literário, filosófico, teve como pressuposto o 
eurocentrismo. O espaço acadêmico brasileiro herda dessa ciência ocidental, nos termos de Said (1990), o poder semiótico europeu de significar o outro.

É uma ciência que ainda conserva uma vontade de poder sobre negros e indígenas, por isso entendemos Ailton Krenak quando no Seminário Antropologia e Seus Espelhos, realizado pelo Programa de Pós-Graduação em Antropologia Social da Universidade de São Paulo em 1994, diz: o que nós sentimos ao longo desse tempo é que tudo que o branco pode saber sobre nós foi usado contra nós... Mas eu sempre fico com a desconfiança de que o motor deste estudo e pesquisa não é nenhuma paixão muito espiritual, é um esforço de dominação, controle e manipulação... (SILVA; REIS; SILVA, 1994, p. 14).

Durante todo o século XX, os negros e negras permaneceram um signo ausente do texto visual universitário, geralmente associado ao poder, à autoridade e ao prestígio no Brasil (SEGATO, 2005). No entanto, chegamos ao século XXI com um novo sujeito político em disputa pela universidade - os Movimentos Negros, subvertendo o foco de atenção, centrado no ensino básico e fundando uma atuação política num novo lugar - o ensino superior brasileiro. Isso tudo contribui para marcar um novo processo político na história recente dos movimentos sociais negros, pressionando o Estado brasileiro no sentido de que assuma a responsabilidade da promoção de políticas para redução das desigualdades entre brancos e negros no Brasil. Esse novo cenário tem propiciado um processo de conquistas de direitos historicamente negados à população negra. Nele, a universidade é percebida por esse novo ativismo negro, a partir dos anos 2000, como um espaço estratégico de formação das populações racialmente discriminadas e empobrecidas.

\section{Desafios epistemológicos da universidade brasileira}

Por outro lado, esse cenário também tem provocado, nos setores intelectuais e socialmente privilegiados da sociedade brasileira, a explicitação pública de novas formas de expressão do racismo para se contrapor a políticas públicas voltadas para a garantia de direitos para as populações negras historicamente discriminadas no país. Exemplo expressivo disso foram as manifestações contrárias ao processo de implantação de políticas afirmativas para inclusão da população negra na Universidade Federal do Rio Grande do Sul, em 2007. Nos muros das ruas de Porto Alegre (RS), apareceram pichações: "Negro só se for na cozinha do 
RU (Restaurante Universitário), Cotas, não", e "Macaco é no zoológico" e ainda "Voltem para senzala".

A universidade do século XXI, na qual chegam esses novos sujeitos, mantêm fortes traços de colonialidades que permaneceram dessa experiência colonizadora e de escravidão racial no Brasil. O ensino superior surge em plena dominação colonial portuguesa, início do século XIX no Brasil e, para atender a seus interesses, produz um conhecimento que transforma o poder de brancos brasileiros sobre negros e indígenas em verdade científica. Esse conhecimento sobre os negros e indígenas no século XIX no Brasil foi, então, gerado pela força do colonialismo escravista, criando-nos como outro, polarizando a distinção - assentada numa desigualdade ontológica entre a Europa e seu Outro - para nos tornar cada vez mais absolutamente outros. Os intelectuais brasileiros vinculados a essas instituições de ensino superior do século XIX e início do século XX escolheram aquela ciência a que Said (1990) se refere como uma severa divisora da humanidade em raças superiores e inferiores.

A universidade como lugar também de negros e negras é experiência que reclama mudanças epistemológicas. Em 2013, circulou nas redes sociais do Brasil imagens de um trote com conotações sexistas, racistas e nazistas, realizado por estudantes veteranos do curso de Direito da Universidade Federal de Minas Gerais com estudantes calouros, no qual retratavam duas cenas. Na primeira, um calouro amarrado a uma pilastra tem, ao lado, três veteranos que fazem a clássica saudação nazista, erguendo o braço direito. Na segunda, outro veterano segura a coleira de uma caloura, pintada de preto, com o cartaz "Caloura Chica da Silva".

Em 2014, um professor da Universidade Federal do Espirito Santo (UFES) foi denunciado à Ouvidoria (SÁ, 2016) dessa universidade por estudantes do curso de Ciências Sociais, por ter feito declarações racistas dentro da sala de aula, durante uma discussão sobre cotas raciais. Os estudantes se sentiram ofendidos pelo pronunciamento em sala de aula do Professor que afirmava críticas às cotas raciais e afirmava preferir ser atendido por um médico branco que um negro. A UFES demitiu o professor após instalar sindicância. O Ministério Público solicita que o Professor seja julgado por racismo. O juiz rejeita tal solicitação e exige que a UFES readmita o professor, alegando várias motivações, dentre elas que o acontecimento ocorreu em uma Universidade, "na qual é normal a coexistência de diversos tipos de pensamentos, inclusive retrógrados".

Em 2015, é a vez da Universidade Federal da Bahia realizar trote com calouros da Faculdade de Arquitetura que deu margem a ser lido como expressão do racismo, ao usar um 
boneco de cor preta enforcado para receber e simbolizar os calouros. Tal imagem foi disseminada nas redes sociais do Brasil. Em artigo intitulado $O$ estranho caso de um inocente boneco preto pendurado na UFBA, publicado no Portal Geledés, a imagem da Faculdade de Arquitetura foi comparada ao contexto de negros e negras que foram enforcados e esquartejados por desafiarem a dominação escravista no Brasil, a exemplo da Revolta dos Búzios, ocorrida também em Salvador (BA). No artigo, a autora se pergunta se o caso da Faculdade de Arquitetura da UFBA não seriauma forma de repudiar a ousadia que negros e negras estão tendo, cada vez mais, apesar de passos tímidos, em entrar no espaço branco da Universidade.

Ainda há grandes desafios para que o Brasil supere a colonialidade - com suas hierarquias raciais, de gênero e epistemológicas - que teima em permanecer na nossa contemporaneidade. Ainda que as universidades brasileiras estejam adotando políticas de ampliação do acesso dos negros como resultado da luta política dos Movimentos Negros, há uma grande dificuldade de operarem mudanças epistemológicas que valorizem a diversidade étnico-racial e contemple os saberes e fazeres da cosmovisão africana e suas diásporas na produção de conhecimento. A inserção dos negros e negras na universidade brasileira tem que ser espaço de disputa epistêmica pois nela somos colocados de frente com o conhecimento eurocentrado transmitido pela academia brasileira. A universidade do século XXI no Brasil, caracterizada pela recente entrada de uma diversidade de sujeitos que historicamente ficaram de fora dela - negros e negras, quilombolas, indígenas -, precisa ter circulando nela, também, os conhecimentos diversos produzidos pela história e cultura desses sujeitos.

A jovem ativista e acadêmica negra Jaqueline Santos, refletindo sobre a produção intelectual de mulheres negras, relata sua experiência de sete anos na universidade, cursando graduação e mestrado em Ciências Humanas:

[...] tive pouco contato com intelectuais negras e negros, africanas e africanos, que transgrediram o pensamento tradicional, e posso afirmar que se não fosse o meu interesse em buscar a contribuição que os mesmos trouxeram para a minha área de pesquisa, teria, ao longo desses anos, uma formação totalmente branco-ocidental. Posso dizer também que o pouco contato que tive com produções intelectuais indígenas partiu do meu próprio interesse (...) De todo o referencial teórico apresentado a mim pela universidade, as produções de mulheres não superaram os $10 \%$, e se levar em consideração a produção intelectual das mulheres negras, esta foi nula, nunca nenhum professor me indicou uma referência teórica deste segmento, mesmo sabendo da existência de Lélia Gonzalez, Petronilha Betriz Gonçalvez, Nilma Lino Gomes, Sueli Carneiro, Bell Hooks, Patrícia Hill Collins, Edna Roland, Deise Benedito, Maria Beatriz Nascimento, Luiza Bairros, Conceição Evaristo, Makota 
Valdina e tantas outras (...) que produzem conhecimento em seus diferentes campos: na academia, na música, no terreiro, na comunidade, na política, nas ruas e etc." (LIMA, 2015, s/p)

Jaqueline está se referindo a uma das manifestações do que estamos chamando de racismo epistêmico: a presença rara de autores negros e negras nas bibliografias dos cursos ministrados nas universidades. Nós, estudantes negros e negras, nos deparamos com essa ausência em maior medida nos cursos de graduação, mas também nos cursos de pós-graduação. Figueiredo e Grasfoguel (2007, p. 36) registram um dos impactos dessa ausência: Consequentemente, poucas vezes temos tido a oportunidade de conhecer a contribuição desses autores, refletindo, inclusive, não apenas sobre o conteúdo de seus trabalhos, mas sobre o contexto político-intelectual em que foram produzidos. Dados relativos à quantidade de docentes com doutorado em universidades brasileiras, apresentados no V Congresso Brasileiro de Pesquisadores Negros e Negras (2008), chamam a atenção para o fato que as mulheres negras vêm sendo prioritariamente atingidas pelo racismo epistêmico no Brasil: são 21 mil homens brancos com doutorado, 16.854 mil mulheres brancas, 374 homens negros e, apenas, 251 mulheres negras.

Para os negros e negras, a universidade tem promovido prisões e produzido encarceramentos diversos, inclusive epistemológicos (HARNEY; MOTTEN, 2014). Lima (2001, p. 307) conta a experiência traumatizante vivido por ele como aluno regular do Programa de Pós-graduação em Antropologia e Sociologia da Universidade de Brasília, considerado de excelência pela CAPES:

Entretanto, neste programa tenho vivenciado experiências que exatamente não me inscrevem pelo meu mérito intelectual, mas como sujeito constituído, sobretudo, através da experiência histórica discursiva da minha condição racial. Pensar sobre esta experiência na UnB, portanto, é tentar historicizar a identidade daquilo ou daqueles que a produziram, é ordenar e interpretar os domínios e ações sociais que me revelaram como negro inferior, suspeito, estrangeiro, fora de lugar, desestabilizador.

Em 1998, Lima (2001) era o único doutorando negro e o primeiro em toda a história do curso de doutorado. Sua decisão em ir para a UnB, diz, apostava na positividade do deslocamento espacial, temporal e de hierarquia social, no enriquecimento intelectual e humano que um programa tido como de excelência, instalado numa cidade atípica e inóspita, poderia me oferecer (p. 307), no entanto: Negro, homossexual, baiano, egresso de outra área 
disciplinar, num meio conservador, tornei-me potencial vítima e agente desestabilizador de uma estrutura social cujo curso regular das normas desconhecia (Idem). E diz mais:

Qual é de fato a minha autonomia para representar esta experiência, se estou aprendendo a falar sobre raça e racismo no Brasil justamente com aqueles sobre os quais levanto uma suspeita? Esta é uma condição de subalternidade que me silencia. Tenho experimentado a inferiorização, o isolamento, a comprovação de quão perversa é qualquer tentativa de inserção social de um negro no meio acadêmico brasileiro. Estou comprovando também que a legitimação de Pelé, da mulata ou a minha própria, assim como a de outros jovens intelectuais afro-brasileiros, tende a ser no mínimo tortuosa. E é no meio acadêmico, onde a presença negra não é nada "natural" ou ainda não foi naturalizada como a presença branca, que o sujeito negro se debate mais violentamente contra a negação da inferioridade atávica, a assimilação embranquecedora ou o estabelecimento do confronto intelectual (LIMA, 2001, p. 311).

As entrevistas com estudantes negros e negras que estavam na universidade em 2005, realizadas para minha dissertação do mestrado, apontaram algumas dessas prisões vividas pelas estudantes negros e negras na universidade (CARDOSO, 2005). Márcio Paim, ex-aluno do Instituto Steve Biko - organização negra que desde os anos 90 prepara jovens negros e negras para inclusão na universidade - narra que, quando entrou na universidade, estava fazendo leituras de uma literatura afro-diaspórica, fruto do interesse que inicialmente já trazia pela questão racial, despertada pelas músicas de Bob Marley e que foi fortalecida pelo Instituto Steve Biko - Malcom, Martin Luther King, Abdias do Nascimento. Foi forçado a abandonar essa literatura em favor de uma carga de leitura que a Universidade requisitava, completamente distante dos seus interesses:

Então, eu tava começando a ler essa coisa, aí de repente quando eu chego na universidade, aí você pega um texto de Marx! Tá entendendo? Aí você vai estudar Fenomenologia do Espírito, Hegel. Aí eu digo - rapaz, que negócio é esse aqui, rapaz? Aí Teoria de História I, aí você vai estudar o positivismo, você vai estudar a Escola dos Anais, você vai estudar esse pessoal. Isso no início fez uma confusão na minha cabeça... (Márcio Paim, entrevista em fevereiro de 2005).

A ex-aluna Nívea Santana do Instituto Steve Biko, por sua vez, relata uma cena que viveu na universidade que se torna cada vez mais comum no ambiente acadêmico brasileiro, após as políticas afirmativas de inclusão dos negros e negras na universidade. São conflitos em sala de aula envolvendo professores e professoras e estudantes negros e negras - de uma lado, 
professores e professoras com narrativas oriundas de sua formação universitária na qual histórias únicas sobre os negros e negras brasileiros são ensinadas, reproduzindo estigmas e estereótipos; por outro lado, estudantes negros e negras oriundos de organizações negras nas quais são apresentadas outras histórias sobre negritudes, contadas a partir dos próprios negros e negras:

Foi aí que, numa discussão em sala, a professora de Turismo foi falar do início do turismo na história, aquela coisa toda e aí eu disse à professora que os primeiros habitantes da Terra eram negros e aí se levantou aquela polêmica, todo mundo em cima de mim... Na aula de Teoria do Turismo e a gente já tinha discutido tudo isso na Steve-Biko. Eu me lembro bem que então foi uma aula assim que de lá eu puxei para faculdade e todo mundo veio em cima de mim e de Naiana (Nívea Santana, entrevista em janeiro de 2005).

Os conflitos surgem diante da consciência dos estudantes negros e negras dos encarceramentos epistemológicos que a universidade promove, pois, em outros momentos, muitas vezes a reação dos estudantes negros era o silêncio, que poderia significar internalização da inferiorização promovida por aquelas histórias únicas no ambiente acadêmico.

Não podemos dizer que isso ocorra só nas universidades brasileiras. Harney e Motten (2014) iniciam seu artigo A Universidade e seus undercommons afirmando que a única relação com a universidade hoje é criminal (HARNEY; MORREN, 2014, s/p) e, utilizando do empréstimo a frase Para ir à universidade eu roubarei, e lá eu roubarei, defendem que essa é a única relação possível com a universidade americana hoje. E completam: Pode ser verdade para as universidades em toda parte. Talvez tenha que ser verdade para a universidade em geral. Mas, certamente, isto é certo ao menos nos Estados Unidos (Idem, s/p). Para eles, a universidade é um lugar de refúgio e não de esclarecimento, lugar no qual

[...] só se pode entrar furtivamente na universidade e roubar o que for possível. Abusar da sua hospitalidade, maldizer sua missão, juntar-se às suas colônias de refugiados, ao seu acampamento cigano, estar dentro, mas não ser dela - este é o caminho do intelectual subversivo na universidade moderna. (Idem, s/p)

Assim, podemos dizer que há um racismo epistêmico nas universidades brasileiras que faz com que o conhecimento acadêmico brasileiro seja dominado por uma razão brancoocidental e marcada por um conhecimento "universal", oriundo das particularidades brancoeuropeias que toma o local como global (GILROY, 2001). Para Carvalho (2003), há um 
racismo acadêmico que impera na universidade, para além do racismo na sociedade, que fez com que, apesar das universidades brasileiras crescerem ao logo de cem anos, os negros ficaram sistematicamente de fora e estas se constituíssem em espaços tão brancos. A conquista da inserção acadêmica é um passo decisivo, mas não suficiente para superarmos o racismo operado na vida acadêmica brasileira. Para nós, esse racismo é também um racismo epistêmico, ou seja, um racismo entranhado nos saberes e na produção de conhecimento, resultado da colonialidade de poderes no Brasil, entendida como um padrão configurado de poder sobre a base da classificação racial que tem servido para subalternizar não só os grupos negros, mas seus conhecimentos (QUIJANO, 2005).

O racismo epistêmico na universidade brasileira se expressa através da exclusividade da epistemologia branco-europeia fundamentada numa busca de uma universalidade também eurocêntrica e da exigência por uma "objetividade" que nega o status de conhecimento à produção negra sobre negritude, dicotomiza saber negro-militante x saber acadêmico-científico e estuda o outro sempre como objeto. Classificar a produção intelectual negra como militante é uma violência epistêmica, nos termos de Spivak (2003). Tal violência que visa, mais uma vez, nos remeter ao lugar de objeto de conhecimento, com o intuito de desqualificar e deslegitimar a intelectualidade negra. As consequências do racismo operado na vida acadêmica brasileira têm dificultado a consolidação de uma intelectualidade negra na universidade, minimizado a produção de intelectuais negros e isolando o intelectual negro politicamente comprometido com a luta contra o racismo (FIGUEIREDO; GRASFOGUEL, 2007).

Lima (2001) reflete sobre a condição de objeto do negro no meio acadêmico-brasileiro, especialmente na área da antropologia, onde tem sido representado cientificamente por intelectuais brancos nacionais e estrangeiros no Brasil, no qual

o negro tem sido constituído como `excesso etnográfico', 'resíduo de África' e deslocamento social em relação às 'branquitudes', que estes mesmos pesquisadores representam em seus campos de investigação. [...] Minha voz subalterna fala então não apenas de uma opressão econômica e racial, mas também de um passado histórico de inacessibilidade a campos de saber e poder legitimados, da contenção de símbolos e valores negro-africanos, da restrição à palavra e da dificuldade do uso de categorias e conceitos que traduzam a minha experiência como intelectual negro na academia brasileira. (LIMA, 2001, p. 283-284).

O que caracteriza o foco do antirracismo acadêmico, num cenário posterior ao maior acesso à universidade, possibilitado pelas políticas de ações afirmativas, é a preocupação com 
a relação entre universidade, produção do conhecimento e ideologias/práticas racializadas que não oportunizam a emergência ou a visibilidade de uma produção intelectual negra (WALSH, 2004). Dessa forma, precisamos refletir sobre os novos desafios postos à universidade e aos movimentos negros brasileiros, após a conquista de políticas de ampliação do acesso de negras e negros à universidade, no que diz respeito ao enfrentamento do racismo epistêmico presente no campo acadêmico, visando à difusão no meio acadêmico-universitário de um conhecimento "descolonizado" a partir das práticas político-culturais e intelectuais negras.

\section{Descolonização do conhecimento em perspectiva negra.}

A entrada dos movimentos negros na disputa pela universidade brasileira, o que só ocorre em finais do século XX, e a vitoriosa conquista da ampliação do acesso dos negros e negras nesse prestigiado espaço, no início do século XXI, abriu uma agenda de descolonização do conhecimento no Brasil. Nessa perspectiva, consideramos que o conhecimento crítico ao racismo/sexismo epistêmico, formulado pelos negros e negras brasileiros e expresso através de sua estética, cultura e política, nos termos de Gilroy (2001), pode contribuir para enfrentamento do que Grosfoguel (2013) denomina de privilégio epistêmico - o cânone do pensamento das ciências humanas nas sociedades ocidentalizadas é constituída das experiências sócio-históricas de homens brancos de apenas 5 países ocidentais: Itália, França, Estados Unidos, Inglaterra e Alemanha. Consideramos, especialmente, que os saberes negros presentes nos terreiros de matriz africana, na política negra, nas rodas de capoeira e nas comunidades quilombolas podem contribuir para a descolonização do conhecimento acadêmico no Brasil, pois são espaços negros de produção de conhecimento que, ainda que afetados pelos poderes coloniais através da estratégia de criminalização, sua história de abandono pelas autoridades republicanas e democráticas a partir do pós-abolição, talvez motivados pela lógica do “deixar morrer”, os converteram em espaços de epistemologias de resistência.

É nesse sentido que consideramos a crítica decolonial latino-americana estratégica para o Brasil nesse momento, pois se constitui como uma crítica ao eurocentrismo a partir dos saberes silenciados e subalternizados na América Latina, propondo uma perspectiva epistêmica que parta de lugares étnico-raciais subalternos para formulação de uma teoria crítica decolonial. Tomamos o conceito de racismo/sexismo epistêmico dessa crítica decolonial para pensar o 
silenciamento de negros e negras nas universidades brasileiras. Grosfoguel (2016) toma o conceito de racismo de Fanon - uma dominação de hierarquia global de superioridades e inferioridads sobre a linha do humano - para entender o racismo epistêmico como una jerarquía de dominación colonial donde los conocimientos producidos por los sujetos occidentales (imperiales y oprimidos) dentro de la zona del ser es considerada a priori como superior a los conocimientos producidos por los sujetos coloniales no-occidentales en la zona del no-ser (p. 98). Tal racismo epistêmico tem a pretensão de que

el conocimiento producido por los sujetos pertenecientes a la zona del ser desde el punto de vista derechista del 'Yo' imperial o desde el punto de vista izquierdista del 'Otro' oprimido occidental dentro de la zona del ser, es automáticamente considerado universalmente válido para todos los contextos y situaciones en el mundo (GROSFOGUEL, 2016, p. 102).

Como consequência, domina globalmente uma epistemologia imperial/colonial que impõe seus esquemas teóricos pensados para contextos muito distintos das situações da zona do não-ser e desconsidera a produção teórica produzida a partir desta. Mesmo a teoria crítica produzida na zona do ser, para a crítica decolonial, é insuficiente para compreender a experiência histórico-social de sujeitos posicionados na zona do não ser pelo racismo e que, portanto, vivem uma violência constante ou "um estado permanente de guerra", de acordo com Maldonado (2017), produzida por uma forte opressão racial. É a partir dessa crítica que emergiu o projeto de tornar visível a experiência intelectual de negros e negras como estratégia de combate ao racismo/sexismo epistêmico no Brasil. Nessa perspectiva pós-colonial latinoamericana é que precisamos cartografar as teorias e práticas ativistas e intelectuais de descolonização do conhecimento desenvolvidas a partir das fronteiras do sistema-mundo moderno colonial brasileiro, contribuindo para revelar histórias e epistemologias esquecidas e marginalizadas pelo racismo e pelo eurocentrismo no Brasil. Necessitamos dar visibilidade à experiência social dos grupos negros e seus conhecimentos, desconstruindo o silêncio epistêmico sobre os seus saberes subalternizados e rebaixados a formas de saber não epistêmicos ou acadêmicos, como expressão da colonialidade presente na sociedade brasileira contemporânea.

Consideramos que o conhecimento crítico ao racismo epistêmico formulado pelos negros brasileiros e expressos através da sua estética, cultura e política pode contribuir para o enfrentamento dos regimes únicos de referência epistemológica, promovendo uma maior 
diversidade epistêmica na academia brasileira. Uma das estratégias para o enfrentamento do racismo epistêmico é tornar visível os conhecimentos críticos e descolonizadores formulados pelos negros e negras brasileiras, colocando o Brasil na rota latino-americana dos estudos póscoloniais/pós-ocidentais. Se a violência do racismo epistêmico nos impõe uma episteme que torna a fala do subalterno negro e negra silenciosa, desqualificada, nossa tarefa como intelectual decolonial é ampliar o número de falantes que atuam diretamente na produção de conhecimento como estratégia de subversão das estruturas de subalternização.

Assim, nos termos dos estudos decoloniais, apresento a "episteme de fronteira" de intelectuais negros e negras do Brasil, que, afetados pelo racismo/sexismo epistêmico, ainda têm ficado de fora da universidade brasileira do século XXI. Meus estudos estão, como afirmou Sueli Carneiro (2007, p. 12), referindo-se ao trabalho de Ratts sobre Beatriz Nascimento:

[...] intencionalmente voltados para o reposicionamento de `saberes sepultados' que compõem o patrimônio político/cultural e libertário do povo negro, expressam um projeto de investimento no resgate de uma `linhagem de pensamento e de ação', e consequentemente de afirmação de sujeitos do conhecimento historicamente desprezados".

Os intelectuais e/ou ativistas negras e negros silenciados nas Ciências Sociais brasileiras vêm dando importantes contribuições ao Brasil e à América Latina, apesar de invisíveis, seja oferecendo novos aportes teóricos, metodológicos e epistemológicos, seja formulando conhecimento crítico ao eurocentrismo e ao racismo. Um deles é Manuel Querino que, num contexto de importação pelos intelectuais brasileiros das teorias racistas produzidas na Europa para a afirmação da inferioridade dos não-brancos - a exemplo de Nina Rodrigues, Silvio Romero, Oliveira Viana -, escreve, em 1918, artigo intitulado O colono preto como fator da civilização brasileira, se tornando um dos primeiros intelectuais a destacar a contribuição do africano e seus descendentes à civilização brasileira e ao enfatizar o Quilombo dos Palmares, com sua forma de organização social, como introdutor do conceito de república no Brasil. Querino promove importantes rupturas com a historiografia tradicional, invertendo a tradicional associação do "preto" com a "barbárie" e como objeto da obra civilizadora do branco português (GLEDHIL, 2014).

São intelectuais e ativistas que têm produzido conhecimento que visibilizem os/as intelectuais negros/as e as suas experiências descolonizadoras do conhecimento, bem como analisam e confrontam com os processos epistemológicos do racismo, a exemplo de Oliveira 
(2007), que pretende ler o mundo desde a experiência afrodescendente no Brasil e, a partir desse lugar, pensa numa epistemologia da ancestralidade. Nessa perspectiva, entende o sistema de Ifá e a capoeira angola como regimes de interpretação do mundo, dentro do qual reaprendemos a ler os signos daquele contexto.

Temos uma produção intelectual de mulheres negras cada vez mais sofisticada no Brasil. No entanto, essa produção intelectual de mulheres negras no espaço acadêmico brasileiro está colocada no mais baixo degrau da hierarquia de conhecimento desse espaço, pois, como lembra Ratts (2007, p. 29), a invisibilidade da mulher negra no espaço acadêmico também se consolida porque o seu outro (homem branco, mulher branca ou homem negro) não a vê nesse ambiente e nem mesmo trilhando esse itinerário intelectual.

Alex Ratts (2007) colocou em visibilidade a trajetória e a relevante contribuição da intelectual e ativista negra Beatriz Nascimento, etc. Beatriz Nascimento, nas décadas de 70 e 80, criticava a historiografia brasileira por fixar a negritude no passado escravista: Quando cheguei na universidade a coisa que mais me chocava era o eterno estudo sobre o escravo. Como se nós só tivéssemos existido dentro da nação como mão de obra escrava, como mão de obra para fazenda e para mineração (NASCIMENTO apud RATTS, 2007, p. 41). Sueli Carneiro, que escreveu o Prefácio da obra de Ratts, após afirmar que Beatriz foi uma historiadora que libertou a negritude do aprisionamento acadêmico ao passado escravista, chama a nossa atenção ao fato de que Beatriz atualizou signos e construiu novos conceitos e abordagens como a noção de quilombos urbanos, conceito com o qual ela ressignifica o território/ favela como espaço de continuidade de uma experiência histórica que sobrepõe a escravidão à marginalização social, segregação e resistência dos negros no Brasil (CARNEIRO, 2007, p. 11).

Sueli Carneiro, por sua vez, é uma das intelectuais e feministas negras, ainda viva, mais importantes que temos no Brasil atualmente. Filósofa, Doutora em Educação e fundadora de uma das primeiras organizações de mulheres negras do Brasil, o Geledés (São Paulo), Sueli Carneiro (2007), uma intelectual negra que tem refletido sobre os efeitos do racismo/sexismo epistêmico, afirma que a invisibilização e silenciamento do pensamento negro têm consistido numa das formas mais eficazes para a permanência e reprodução da alienação cultural e postergamento da emergência e florescimento do pensamento crítico negro (p. 12). A autora foi intelectualmente importantíssima para a defesa das cotas como política afirmativa de ampliação do acesso dos negros e negras às universidades, num momento em que a elite branca 
e acadêmica queria barrá-las com ato de inconstitucionalidade. Defendeu tese de doutorado em 2005, intitulada A construção do outro como não ser como fundamento do ser, na qual, utilizando-se do conceito idealizado por Boaventura Souza Santos de epistemícidio e de dispositivo e biopoder de Foucault, pensa sobre as práticas educacionais que dificultam a trajetória dos negros como sujeito do conhecimento. Nela, Sueli Caneiro (2005) defende que

o dispositivo de racialidade vem se constituindo historicamente em elemento estruturador das relações raciais no Brasil, pois dentre os componentes do dispositivo de racialidade que ele articula, o epistemicídio tem se constituído no instrumento operacional para a consolidação das hierarquias raciais por ele produzidas, para as quais a educação tem dado contribuição inestimável. (p. 33)

Assim, afirma que sua tese é:

um exercício de aplicação de conceitos de dispositivo e biopoder de Michel Foucault ao domínio da racialidade, por meio dos quais busca-se aqui demonstrar a existência de um dispositivo de racialidade/biopoder operando na sociedade brasileira, que, articulando múltiplos elementos, dentre eles o epistemicídio, configua a racialidade como um domínio que produz saberes, poderes e subjetividades com repercussões sobre educação (CARNEIRO, 2005, p. 11)

Por falar em saberes de mulheres negras, emerge como presença soberana Lélia Gonzalez. A trajetória dessa mulher, ativista e intelectual negra e feminista, no momento em que só havia ela, nos permite apresentar as epistemologias feministas, pois, desconfiadas e descontentes com a ciência ocidental e seus pressupostos de objetividade, universalidade e neutralidade, já que necessitavam de uma produção de conhecimento que intervisse sobre o silenciamento e inferiorização das mulheres, as feministas são críticas às epistemologias ocidentais. A partir dessa crítica, as pesquisadoras feministas passam a refletir, investigar e formular epistemologias denominadas de feministas. Lélia Gonzalez contribuiu para o avanço dessa epistemologia feminista na medida em que, tanto no Brasil como na América Latina, produziu conhecimento para alargar a perspectiva das epistemologias femininas, as quais, ainda que críticas às epistemologias ocidentais, pois vítimas dela, reproduzem a sua violência epistêmica ao não problematizar o silenciamento e as múltiplas opressões a que vinham sendo submetidas as mulheres negras e de cor, opressões essas, muitas vezes, protagonizadas pelas próprias mulheres brancas e feministas: Seu texto visava exatamente analisar a situação da mulher negra na sociedade brasileira, considerando a cultura patriarcal e as formas de 
dominação racial exercidas não apenas pelos homens, mas também pelas mulheres brancas (RATTS; RIOS, 2010, p. 102).

Dessa forma, Lélia se alia a feministas negras e de cor da América como Gloria Anzaldúa, Patricia Collins, Bell Hooks, etc., que vêm tencionando o feminismo branco como. Aliás, Lélia descontrói a epistemologia ocidental de diversas formas, pois, além de desafiar o feminismo branco no Brasil, desafia a colonialidade dos partidos políticos de esquerda brasileiros, por não incorporar a luta contra o racismo como uma das agendas centrais num país como o Brasil - "de uma maioria negra silenciada". Ainda, desafia os próprios Movimentos Negros que ajudou a formar e fortalecer, pois expõe o escondido, mas usufruído privilégio branco dos seus ativistas negros dado pelo lugar de gênero: a reprodução do privilégio de gênero na relação com as mulheres negras, inclusive a crítica de que homens negros têm sido vítimas do ideal estético do "branco belo". Lélia, então, inaugura no Brasil o denominado feminismo negro, ou seja, a reflexão e ação política em torno do gênero a partir do lugar de negras.

No excelente trabalho biográfico de Ratts e Rios (2010) sobre Lélia Gonzalez, tais pesquisadores demonstram o quanto Lélia tem sido reconhecida dentro e fora do Brasil:

Lélia Gonzales é verbete do Dicionário de Mulheres do Brasil, da Enciclopédia da diáspora africana e da Enciclopédia Encarta Africana. Alguns de seus artigos são citados em trabalhos contemporâneos escritos em português, inglês, espanhol e francês, os quais abordam as relações raciais e de gênero. Desde o ano de 1999, como veremos, vasto material tem sido escrito sobre as ideias e a vida dessa ativista. (p. 13).

O que valeria averiguar é se tanto reconhecimento implica que a obra de Lélia Gonzales já tenha entrado para as bibliografias dos cursos de graduação e pós-graduação no Brasil, será?

\section{Conclusão}

O ensino superior foi criado no século XIX para fortalecer o colonialismo português com a vinda da Coroa para o Brasil, reproduzindo sua violência epistêmica. A universidade que surge na década de 30 do século XX, reproduz a colonialidade do poder/saber de diversas formas: toma as universidades europeias modernas como modelo de organização do conhecimento, instaura a relação epistemológica sujeito branco/objeto negro e indígena; instala o exclusivismo da epistemologia ocidental, excluindo, silenciando e desqualificando saberes 
negros e indígenas, etc. Só em finais do século XX e início do século XXI, os movimentos negros entram na disputa pela universidade brasileira, pois, até então, ela era o lugar da brancomestiços brasileiros, identificados - tanto do ponto de vista étnico-racial e dos interesses sócioeconômicos quanto do ponto de vista epistemológico -com a eurodescendência. A partir dos anos 2000, é deflagrado diversos movimentos de estudantes e docentes negros e negras exigindo, do Estado, políticas de ampliação do acesso de negros e negras às universidades. Com a entrada de negros, negras, indígenas e quilombolas nas universidades brasileiras, abre-se, no Brasil, a agenda da descolonização do conhecimento acadêmico. Apresentar práticas políticoculturais e intelectuais negras com vocação descolonizadora do conhecimento no Brasil e que desafiam, portanto, o racismo epistêmico, visa contribuir para que a universidade brasileira se torne mais diversa epistemicamente e, por conseguinte, menos hostil à diversidade cultural do Brasil, do ponto de vista epistemológico.

\section{Referências}

CARNEIRO. Aparecida Sueli. A construção do outro como não-ser como fundamento do ser. Tese (Doutorado em educação). Universidade de São Paulo, São Paulo, 2005.

. Prefácio. In: RATTS, Alex. Eu sou Atlântica: sobre a trajetória de vida de Beatriz Nascimento. São Paulo: Imprensa Oficial/Instituto Kuanza, 2007.

CARVALHO, J. J. O confinamento racial do mundo acadêmico brasileiro. Revista da USP, n. 22, São Paulo, USP, 2006.

CASTRO, Silvia Regina Lorenzo de. Corpo e erotismo em Cadernos Negros: a reconstrução semiótica da liberdade. Dissertação de Mestrado. São Paulo: Faculdade de Filosofia, Letras e Ciências Humanas da Universidade de São Paulo, 2007.

DURHAM, Eunice Ribeiro. A universidade brasileira: os impasses da transformação. Ciência e Cultura. São Paulo, v. 38, n.12, p. 204-218, dez. 1996.

FIGUEIREDO, Angela; GROSFOGUEL, Ramón. Por que não Guerreiro Ramos? Novos desafios a serem enfrentados pelas universidades públicas brasileiras. Cienc. Cult. v. 59, n. 2, 2007.

FREYRE, Gilberto. Casa Grande e Senzala - formação da família brasileira sob o regime da economia patriarcal. Rio de Janeiro: Record, 1998. 
GREDHILL, Helen Sabrina. Travessias Racialistas no Atlântico Negro: Reflexões sobre Booker T. Washington e Manuel R. Querino. 2014, Disponível em:

$<$ https://www.academia.edu/6578299/Travessias_Racialistas_no_At1\%C3\%A2ntico_Negro_ Reflex\%C3\%B5es_sobre_Booker_T._Washington_e_Manuel_R._Querino $\geq$. Acesso em 13 jan. 2017.

GROSFOGUEL, Ramon. Racismo/sexismo epistémico, universidades occidentalizadas y los cuatro genocidios/ epistemicidios del largo siglo XVI. Tabula Rasa. Bogotá, n. 19, p. 31-58, jul-dez, 2013.

La descolonización del conocimiento: diálogo crítico entre la visión descolonial de Frantz Fanon y la sociología descolonial de Boaventura de Sousa Santos. s/d. Disponível em: $<$ http://www.iepala.es/IMG/pdf/Analisis-

Ramon_Grosfoguel_sobre_Boaventura_y_Fanon.pdf>. Acesso em 06 dez. 2017.

HARNEY, Stefano; MOTTEN, Fred. A Universidade e seus undercommons. 2014.

Disponível em: <http://hemisphericinstitute.org/hemi/en/emisferica-111-decolonialgesture/harney>. Acesso em 06 dez. 2017.

LIMA, Ari. A legitimação do intelectual negro no meio acadêmico brasileiro: negação de inferioridade, confronto ou assimilação intelectual. Afro-Ásia, Salvador, n. 26, p. 281-312. 2001.

MALDONADO-TORRES, Nelson. Outline of Ten Theses on Coloniality and Decoloniality. 2016. Disponível em: <http://frantzfanonfoundationfondationfrantzfanon.com/article2360.html>. Acesso em 15 jan. 2017.

MOURA, Clóvis. Sociologia do negro brasileira. São Paulo: Ática, 1988.

QUIJANO, Anibal. Colonailidade de Poder, eurocentrismo e América Latina. 2005.

Disponível em: <http://biblioteca.clacso.edu.ar/clacso/sur-

sur/20100624103322/12_Quijano.pdf >. Acesso em: 05 out. 2015.

RATTS, Alex. Eu sou Atlântica: sobre a trajetória de vida de Beatriz Nascimento. São Paulo: Imprensa Oficial/Instituto Kuanza, 2007.

RATTS, Alex; RIOS, Flávia. Lélia Gonzalez. São Paulo: Selo Negro, 2010.

RAMOS, Alberto Guerreiro. Introdução Crítica à Sociologia Brasileira. Rio de Janeiro: Editora da UFRJ, 1995.

OLIVEIRA. Eduardo David. Filosofia da Ancestralidade: corpo e mito na filosofia da educação brasileira. Curitiba: Editora Gráfica Popular, 2007.

RODRIGUES, Nina. Os africanos no Brasil. 6. ed. São Paulo: Editora da Universidade de Brasília, 1982. 
SÁ, Carla. Professor demitido após denúncia de racismo vai voltar a dar aulas na Ufes. Gl, publicação online, 16 fev. 2016. Disponível em: <http://g1.globo.com/espirito-santo/educacao/noticia/2016/02/professordemitido-apos-denuncia-de-racismo-vai-voltar-dar-aulas-na-ufes.html >. Acesso em 04 jan. 2017.

SAID, Edward. Orientalismo - O Oriente como invenção do Ocidente. São Paulo: Companhia das Letras, 1990.

SANTOS, Boaventura. As Dores do Pós-colonialismo. Jornal Folha de São Paulo, 21 agost. 2006

SANTOS, Jaqueline Lima. A produção intelectual de mulheres negras e o epistemicídio uma breve contribuição. 2010. Disponível em:

$<$ http://www.institutobuzios.org.br/documentos/Jaqueline\%20Lima\%20Santos_A\%20Produ $\%$ C3\%A7\%C3\%A3o\%20Intelectual\%20das\%20Mulheres\%20Negras $\% 20 \mathrm{e} \% 20 \mathrm{o} \% 20$ Episte mic\%C3\%ADdio.pdf>. Acesso em: 06 dez. 2017.

SEGATO, Rita. Raça é Signo. 2005. Disponível em:

<http://dan.unb.br/images/doc/Serie372empdf.pdf>. Acesso em 15 jan. 2017.

SEYFERT, Giralda. O beneplácito da desigualdade: breve digressão sobre racismo. In: RACISMO no Brasil. São Paulo: ABONG; Peirópolis (SP), 2002, p. 17-45.

SCHWARCZ, Lilia K. Moritz. O espetáculo das raças: cientistas, instituições e questão racial no Brasil - 1870-1930. São Paulo: Companhia das Letras, 1993.

SILVA, Denise Ferreira da. Revisitando a 'democracia racial': raça e identidade nacional no pensamento brasileiro. Estudos Afro-Asiáticos. Rio de Janeiro, n. 16, p. 157-167, 1998.

SILVA, Nádia Maria Cardoso da. Instituto Steve Biko - Juventude Negra Mobilizando-se por Políticas de Afirmação dos Negros no Ensino Superior. Dissertação de Mestrado. Universidade do Estado da Bahia, 2006.

SILVA, Vagner Gonçalves da; REIS, Leticia Vidor; SILVA, José Carlos. (orgs). Antropologia e seus Espelhos: a etnografia vista pelos observados. FFLCH/USP, 1994.

SILVEIRA, Renato. Os selvagens e a massa: o papel do racismo científico na montagem da hegemonia ocidental. Afro-Ásia, 23, Salvador: 2000, pp. 89-14

SPIVAK, Gayatri Chakravorty. Pode o Subalterno Falar? Belo Horizonte: Editora UFMG, 2010.

\footnotetext{
${ }^{\text {i }}$ Doutoranda do Programa de Pós-graduação em Cultura e Sociedade - Instituto de Humanidades Milton Santos Universidade Federal da Bahia (UFBA).
} 